\title{
QUALITY BY DESIGN (QBD) AS A TOOL FOR THE OPTIMIZATION OF INDOMETHACIN FREEZE-DRIED SUBLINGUAL TABLETS: IN VITRO AND IN VIVO EVALUATION
}

\section{MERVAT SHAFIK IBRAHIMa, NIHAL MOHAMED ELMAHDY ELSAYYAD ${ }^{a^{*}}$, ABEER SALAMA ${ }^{\mathrm{b}}$, SHEREEN H. NOSHI ${ }^{\mathrm{a}}$}

aDepartment of Pharmaceutics and Industrial Pharmacy, Faculty of Pharmacy, October University for Modern Sciences and Arts (MSA), Cairo, Egypt, bDepartment of Pharmacology, National Research Centre (NRC), El-Buhouth Street, Cairo, Egypt

Email: nmahdy85@gmail.com

Received: 30 May 2021, Revised and Accepted: 16 Jul 2021

\section{ABSTRACT}

Objective: This study aims to prepare and optimize indomethacin freeze-dried sublingual tablets (IND-FDST) by utilizing a quality by design (QbD) approach to achieve rapid drug dissolution and simultaneously bypassing the GIT for better patient tolerability.

Methods: A screening study was utilized to determine the most significant factors which the quality attributes, namely disintegration time and \% friability. Then an optimization study was conducted using a full response surface design to determine the optimized formula by varying the amount of the matrix-forming polymer (gelatin) and super disintegrant (croscarmellose sodium (CCS)). The variables' effect on the \% friability, disintegration time, wetting time, and amount of drug release after $10 \mathrm{~min}(\% \mathrm{Q} 10)$ was studied. The optimized formula was tested for compatibility, morphology as well as stability studies under accelerated conditions in addition to the in vivo pharmacodynamics in rats. QbD was adopted by utilizing a screening study to identify the significant formulation factors followed by a response surface optimization study to determine the optimized IND-FDST formulation.

Results: Optimized IND-FDST comprised of gelatin/CCS combination in a ratio of 1:1 possessed adequate \%friability $(0.73 \pm 0.03 \%)$, disintegration time $(25.40 \pm 1.21$ seconds), wetting time $(3.49 \pm 0.68$ seconds), and $\%$ Q10 $(100.99 \pm 5.29 \%)$ as well as good stability under accelerated conditions. IND-FDST also showed significant inhibition of edema, tumour necrosis factor-alpha, and interleukin- 6 release in vivo compared to the oral market product by $70 \%, 42 \%$, and $65 \%$, respectively.

Conclusion: QbD presents a successful approach in the optimization of a successful IND-FDST formula that showed superior in vivo and in vitro characteristics.

Keywords: Quality by design, Indomethacin, Freeze-dried tablet, Sublingual tablet, Stability testing

(C) 2021 The Authors. Published by Innovare Academic Sciences Pvt Ltd. This is an open-access article under the CC BY license (https://creativecommons.org/licenses/by/4.0/) DOI: https://dx.doi.org/10.22159/ijap.2021v13i5.42216. Journal homepage: https://innovareacademics.in/journals/index.php/ijap

\section{INTRODUCTION}

Oral drug delivery is the most customarily used route among all other drug administration routes [1] because of its recognizable advantages such as; its ease of application, ameliorate patient compliance, slightest sterility conditions needed, and high flexibility in developing the dosage form $[2,3]$. Now a day's formulation research is breaking barriers of conventional methods to deliver drugs more conveniently with better performance and high bioavailability. Limitations associated with the oral tablets could be solved by using sublingual tablets as an alternative to the oral route [4]. The use of the sublingual route offers various advantages, such as ease of preparation and the ability to bypass the GIT harsh conditions [5]. In addition, the absorption of the drug by the veins located in the mouth floor, leading directly to the superior vena cava [6] combined with a small thickness of 100$200 \mu \mathrm{m}$. Allows faster distribution of the drug through the bloodstream compared to that of orally administered drugs [610]. Freeze-dried sublingual tablets have attracted much attention from researchers as it offers tablets of high porosity which allows better exposure of the drug to the saliva in the mouth resulting in immediate disintegration and dissolution of the tablet when placed under the tongue [11-16].

Non-steroidal anti-inflammatory drugs (NSAIDs) are a heterogeneous drug group broadly prescribed for analgesic, feverreducing, and anti-inflammatory effects $[17,18]$. A model drug for NSAIDs in our study is Indomethacin (IND), a non-selective NSAID that is considered one of the most successful anti-rheumatic drugs and prime drug nominate for the management of pain and/or swelling in many conditions such as osteoarthritis, rheumatoid arthritis $[19,20]$, and joint pains [21], Despite, its high therapeutic efficacy, oral administration of IND causes several adverse effects, such as gastrointestinal ulceration especially upon the repetitive use of the drug with high doses and in cases of self-medication [22, 23] These effects are attributed to the cyclooxygenase (COX) inhibition which impairs the GIT protective barrier function as well as the prolonged contact of the drug with the GIT mucosa. The latter mechanism can be tackled via minimization/elimination of the IND contact with the GIT mucosa via sublingual route can be beneficial as an alternative route to overcome IND side-effects and to benefit from the advantages of this route [24]

Recently, Quality by design (QbD) has harnessed significant attention in the scientific and industrial community to shorten the time needed for the development of formulas with efficient resource allocation [25]. QbD is a regulatory, systematic, knowledge-based system with quality management thinking to ensure the quality of the predefined final target product [26]. QbD necessitates the determination of the quality target product profile (QTPP), and critical quality attributes (CQAs), which critically affect the quality properties of the final product [27]. Scientific knowledge from previously reported literature is the basic source for the selection of material attributes and critical process parameters (CPPs) which can significantly influence the QTPPs [26].

Thus, based on the above considerations, this study aims to develop IND freeze-dried sublingual tablets (IND-FDSTs) to allow a faster onset of action for IND and eliminate the direct contact of the drug with GIT mucosa. A QbD approach was utilized for screening of select factors, namely, matrix former type and amount as well as super disintegrant type and amount. The \% friability and disintegration time were considered CQAs. An optimization formula was then conducted utilizing a response surface design for the determination of the optimized IND-FDST, which will be further tested for stability and compatibility. An additional aim of this study was to compare the anti-inflammatory effect of IND-FDSTs compared to free IND in rats. 


\section{MATERIALS AND METHODS}

\section{Materials}

Indomethacin (IND) was kindly supplied by El Arabeya Co. for Pharmaceutical and Chemical Industries, Cairo (Egypt). Carrageenan and pectin extracted from citrus fruits were purchased from Sigma Aldrich Chemical Co., (St. Louis, USA). Sodium alginate and gelatin were purchased from AVI-CHEM Laboratories, (Mumbai, India). Methocel ${ }^{\circledR}$ E15 was purchased from Colorcon (Dartford, United Kingdom). Crospovidone was supplied by BASF Pharma, Isle of Lewis (UK). Sodium starch glycolate, croscarmellose sodium, and mannitol were obtained from Roquette Pharma (Zaventem, Belgium). Sucralose was kindly supplied from Marcyrl Pharmaceutical Industries (Cairo, Egypt). Glycine, disodium hydrogen phosphate, and potassium dihydrogen phosphate were obtained from El-Nasr Pharmaceutical Chemicals Co. (Cairo, Egypt). Tumour necrosis factor-alpha (TNF- $\alpha$ ) and interleukin-6 (IL-6) were purchased from NOVA (Beijing, China). Distilled water was used throughout the study. All other chemical reagents and solvents were of analytical grade and used as received. Forty adult male Wister albino rats (7-8-weeks old, weighing 130-150 g) were purchased from the National Research Centre animal house (Cairo, Egypt) to be used for the animal studies.

\section{Preparation of indomethacin freeze-dried sublingual tablets (IND-FDSTs)}

IND-FDSTs were prepared by combining matrix-forming polymers (either gelatin, pectin, or $\mathrm{Na}$ alginate) with a super disintegrant (either croscarmellose (CCS), crospovidone (CP), or sodium starch glycolate (SSG)) in distilled water and stirred with a magnetic stirrer till they completely dissolve. After that, glycine was added as a cryoprotectant and mannitol as a bulking agent and allowed to dissolve to give a clear solution. An accurately weighed amount of
IND powder was then dispersed in the prepared aqueous solution using a magnetic stirrer. Then, an accurate volume of the resulted dispersion was transferred into the pocket of a PVC blister pack to give a dose of $25 \mathrm{mg}$ of IND per tablet. The blister packs were freezedried for $24 \mathrm{~h}$ in a lyophilizer (Alpha 1-2 Idplus Christ) under a pressure of 0.02 mbar at- $45{ }^{\circ} \mathrm{C}$. The resultant IND-FDSTs were inspected for the integrity and smoothness of the surface as well as their adhesion to the blisters; the thickness and diameter were also measured using a vernier caliper (Mituyoto, Tokyo, Japan) and presented as mean value \pm standard deviation (SD) to ensure successful preparation and tablet properties.

\section{Quality by design (QbD) and screening study}

Based on literature reviews and preliminary studies, risk assessment was implemented to identify and prioritize all the highrisk material attributes and process parameters that may potentially affect IND-FDSTs. After identifying the critical quality attributes (CQAs), according to ICH8 [26], CQAs for oral tablets can be set as disintegration time and \% drug released at $10 \mathrm{~min}(\% \mathrm{Q} 10), \%$ friability. Ishikawa (fishbone or cause-and-effect) diagram was set up as a graphical tool for highlighting all factors that can influence the CQA of IND-FDST. The diagrams were generated using Minitab ${ }^{\circledR}$ 17 software (Minitab Inc.; State College, PA, USA).

An extensive number of variables from many categories, i.e., materials, formulation, environment, homogenization process, methods, and measurements, etc., presented in the Cause and Effect (Ishikawa) diagram (fig. 1), were reported in the literature. Based on the results of the Ishikawa diagrams, the type and amount of matrix former and super disintegrant were determined to be critical factors for the preparation of IND-FDSTs, which in turn directly affect the disintegration and dissolution. The critical quality attributes (CQA) were set to the $\%$ friability and disintegration time.

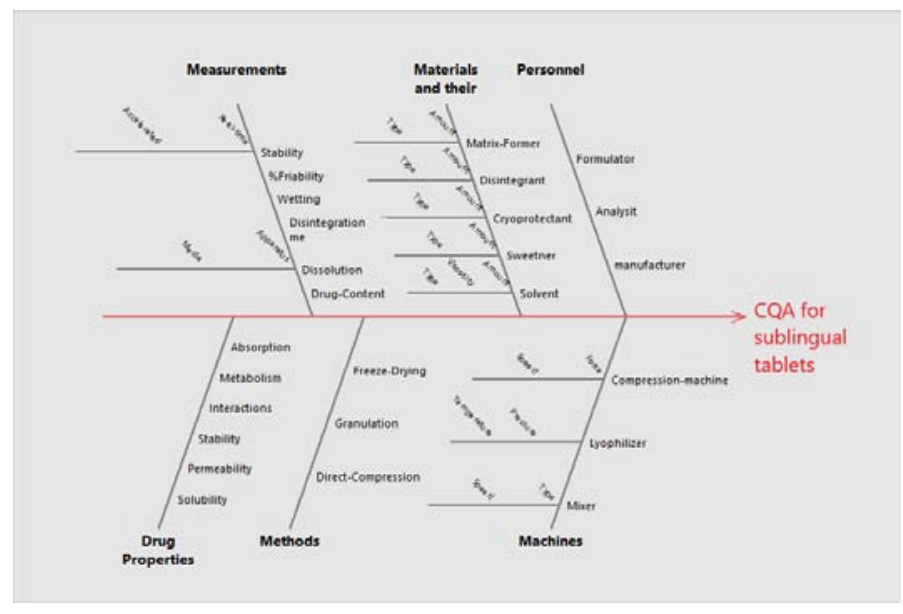

Fig. 1: Ishikawa diagram representing the formulation critical factors and CQAs for preparation of sublingual tablets based on historical data for QbD study

Herein, a screening study was conducted for the determination of the most significant formulation attributes to be included in the optimization study. IND-FDSTs were prepared according to the proposed screening study design using Minitab ${ }^{\circledR} 17$ to determine the most critical attributes affecting the formulation for optimization of the preparation of IND-FDST. The screening design comprised two categorical variables: matrix former type (X1) in three levels (gelatin, pectin, and sodium alginate), super disintegrant type (X2) in three levels (CP, CCS, and SSG) as well as their amount (X3 and X4, respectively) in two levels (0, and $4 \mathrm{mg})$. The most promising formulas were prepared and their CQA's were determined, namely $\%$ friability (Y1) and disintegration time (Y2). All experiments were conducted in triplicates and the data were evaluated for the level of significance for the studied factors on the responses using one-way analysis of variation (ANOVA). The resultant 12 formulas (S1-S12) composition is listed in table 1 . The optimized combination of the mentioned factor will be selected based on the desirability index (D) value with the most desirable formula with a value close to 1 to be included in the optimization study. The optimized formula will be defined as the formula with the least \% friability and the least disintegration time with equal weights for both attributes.

\section{Optimization study for IND-FDSTs}

A response surface design was employed for the optimized matrix former/super disintegrant combination by varying their amounts $(0$, 2, 4, and $8 \mathrm{mg}$ for super disintegrant and 0, 2, 4, $8 \mathrm{mg}$ for matrix polymer) and employing the same preparation method previously described. The selected independent variables were $\%$ friability (Y1), disintegration time (Y2), wetting time (Y3), and \% IND released at $10 \mathrm{~min}(\% \mathrm{Q} 10)(\mathrm{Y} 4)$. All experiments were conducted in triplicates and the data were evaluated for the level of significance of 
the studied factors on the responses using one-way analysis of variation (ANOVA). The resultant 9 formulas (01-09) composition is listed in table 2. The optimized formula was selected based on the D value with the most desirable formula has a value close to 1 to be employed for future studies.

All formulas were evaluated according to their thickness, diameter, weight variation, drug content, friability, disintegration time, and dissolution profile.

\section{Evaluation of IND-FDSTs}

\section{Weight variation}

From each formula, twenty tablets were weighed individually, and the average weight was calculated. The weight variation was calculated using Equation 1 [28].

Weight Variation $(\%)=\frac{\text { Theoretical tablet weight-Average tablet weight }}{\text { Average tablet weight }} \times 100$

\section{Friability}

Friability was determined using an Erweka friability tester (ERWEKA-GmbH, Germany) by introducing ten tablets of each formula after being de-dusted and weighed. The drum of the apparatus was rotated for 100 rotations for 1 minute after which the tablets were removed, brushed, and reweighed. The difference between the weight of the tablets before and after the test was calculated according to Equation 2.

Friability $(\%)=\frac{\text { Initial tablet weight-Final tablet weight }}{\text { Initial tabket weight }} \times 100 \ldots \ldots . .$. (Equation 2)

\section{Drug content}

Five tablets from each formula were powdered using mortar and pestle and an amount equivalent to one tablet was weighed and dissolved in methanol and phosphate buffer $\mathrm{pH} 7$ in a ratio of 1:1 on a rotary shaker overnight so that IND content would constitute $25 \mu \mathrm{g} / 100 \mathrm{ml}$. The solution was then centrifuged and the supernatant was collected and analysed for IND content using a UV-visible spectrophotometer (Shimadzu spectrophotometer 2401/PC, Japan) at $\lambda_{\max } 318 \mathrm{~nm}$ and the concentration of the drug was calculated from the constructed calibration curve (USP 41/NF 38)[29]. The measurements were repeated $(n=3)$ and the average drug content was calculated according to the following equation [30]:

$$
\text { Drug content }(\%)=\frac{\text { Actual drug content }}{\text { Theoretical drug content }} \times 100 \ldots \ldots . . . .(\text { Equation } 3)
$$

\section{Wetting time}

A sample of $10 \mathrm{ml}$ of methylene blue dye in distilled water was placed in a Petri dish of $10 \mathrm{~cm}$ diameter. One tablet was carefully placed in the center of the Petri dish and the time required for water to reach the upper surface of the tablet was measured and noted as the wetting time. The test results are presented as the mean value of three determinations \pm SD $[31,32]$.

\section{Disintegration time}

The disintegration times were determined in vitro by a USP disintegration tester (PTZ Auto 1 A, Pharma test, Germany) at 37 ${ }^{\circ} \mathrm{C} \pm 2{ }^{\circ} \mathrm{C}$ (USP $41 / \mathrm{NF}$ 38) using distilled water as disintegration medium [29]. One tablet was introduced into each of the six tubes of the basket and the time required for complete tablet disintegration was recorded. The mean \pm SD of the six tablets was calculated.

\section{Evaluation of the optimized IND-FDST}

\section{In vitro dissolution studies}

The dissolution profiles of the optimized IND-FDST was compared to the pure drug $(25 \mathrm{mg})$ and the current marketed product of IND (Indocin ${ }^{\circledR}$ capsules) of the same strength as well as formulas S1, S3, and S10 comprising $\mathrm{Na}$ alginate, gelatin, and pectin, respectively as matrix formers with the same ratios of all other excipients for comparison purposes. The experiments were carried out in triplets for each sample in a USP rotating paddle apparatus (Hanson SR8plus, USA). The dissolution media was $750 \mathrm{ml}$ of phosphate buffer $\mathrm{pH} 7.4$ and distilled water in ratio 1:4 (USP media) [29], the temperature was kept at $37 \pm 0.5^{\circ} \mathrm{C}$ and the paddle rotation speed was set to $100 \mathrm{rpm}$. Samples were withdrawn at 1, 2, 3, 5, 7, 10, 15, and $20 \mathrm{~min}$. The sample volume was $5 \mathrm{ml}$ of dissolution medium which was replaced by an equal volume of fresh buffer to maintain a constant total volume. Samples werefiltered using a syringe filter of $0.45 \mu \mathrm{m}$ Millipore and the drug concentration was spectrophotometrically assayed (Shimadzu spectrophotometer 2401/PC, Japan) at $318 \mathrm{~nm}$ after appropriate dilution with dissolution media. The dissolution profiles were compared using similarity factor (f2) defined by Equation (4) [33]

$$
\mathrm{f} 2=50 \log \left\{\left[1+\frac{1}{\mathrm{n}} \sum_{\mathrm{t}=1}^{\mathrm{n}} \mathrm{Rt}-\mathrm{Tt}\right]^{-0.5}\right\} \mathrm{x} 100 \ldots \ldots \ldots \text { (Equation 4) }
$$

Where, $\mathrm{n}=$ the number of sampling time points, $\mathrm{Rt}=$ mean $\%$ dissolved of the reference at a given time point $\mathrm{t}, \mathrm{Tt}=$ mean $\%$ dissolved of the test at the same time point $t$. The similarity factor fits the result between 0 and 100. For two dissolution profiles to be considered similar, f2 values should be higher than 50 , whereas smaller values imply dissimilarity between dissolution profiles [34].

\section{Differential scanning calorimetry (DSC)}

DSC scanning was done for pure IND, mannitol, the physical mixture, and the optimized IND-FDST. Scanning was carried out using a differential scanning calorimeter (Perkin Elmer, Germany) by heating $5 \mathrm{mg}$ of the tested sample in sealed aluminum pans from ambient temperature to $200^{\circ} \mathrm{C}$ at a linear heating rate of $10^{\circ} \mathrm{C} / \mathrm{min}$ under atmospheric nitrogen. The resultant thermograms were compared.

\section{Fourier-transform infrared spectroscopy (FT-IR)}

IR spectra of the pure drug, physical mixture, the selected IND-FDST, and all the excipients individually were recorded on FTIR spectrophotometer (Perkin Elmer, Germany) at a scanning range from $500-4000 \mathrm{~cm}^{-1}$ and resolution of $4 \mathrm{~cm}^{-1}$ [35].

\section{Powder X-ray diffraction (XRD)}

Diffraction patterns for pure IND, the selected IND-FDST, and their corresponding physical mixtures were obtained using Scintag X-ray diffractometer (Massachusetts, USA) using $\mathrm{Cu} \mathrm{K \alpha}$ radiation, and a voltage of $45 \mathrm{kV}$ [36].

\section{Scanning electron microscopy (SEM)}

Samples were cut from the selected formula using a blade and observed by Jeol JSM-6400 scanning electron microscope (Jeol Ltd., United States of America) for surface and section view [37].

\section{Accelerated stability study}

The stability of the optimized IND-FDST formula was studied in an accelerated stability study. Tablets were stored in glass containers and kept in the stability chamber (Votsch, VP600, Germany) at $40{ }^{\circ} \mathrm{C} \pm 2{ }^{\circ} \mathrm{C}$, $75 \% \pm 5 \%$ RH for six months according to the ICH guideline (Q1A (R2) section 2.1.7.1) [38,39]. The physical appearance, drug content, disintegration time, and in vitro dissolution for IND-FDST tablets were chosen to be the stability determining attributes. Thus, the aforementioned factors were re-determined after storage and compared to the freshly prepared formulation for any significant changes.

\section{In vivo pharmacodynamics}

\section{Animals}

Forty adult male Wister albino rats (7-8-weeks old, weighing 130$150 \mathrm{~g}$ ) were purchased from the National Research Centre animal house (Cairo, Egypt) and housed in standard cages (10 rats per cage), under specific pathogen-free conditions in facilities maintained at controlled room temperature $\left(21-24{ }^{\circ} \mathrm{C}\right)$ with a relative humidity of $40-60 \%$ and under normal dark-light cycles. All animals had free access to a rat chow diet and water ad libitum. The rats were acclimatized for two weeks before the start of the study in the laboratory of the National Research Centre, Cairo, Egypt. All procedures followed the Helsinki Declaration as well as specific 
national laws. This experiment was carried out in accordance with the Ethics Committee of the National Research Centre, Egypt, and followed the National Institutes of Health Guide Recommendations Care and Use of Laboratory Animals (Publication No. 85-23, revised 1985). The procedures were approved by the Ethical Committee of the October for Modern Sciences and Arts (MSA) University (approval number: Pt18/Ec18/2019 F).

\section{Carrageenan induced paw Edema}

Paw swelling was induced by the sub-plantar injection of $100 \mu \mathrm{l}$ of $1 \%$ sterile lambda carrageenan suspended in saline into the right hind paw $[40,41]$. The contralateral paw received an equal volume of saline as a control. The inflammation was quantified by measuring the hind footpad before carrageenan injection and one to four hours after carrageenan injection with a micrometer caliper [42]. Edema was expressed as a percentage of change from control (pre-drug) values. Animals were divided into four groups each of ten rats. The 1st group: Rats received orally saline $(0.2 \mathrm{ml} / \mathrm{rat})$ as control, 2 nd group: Rats were injected with carrageenan, 3rd group: Rats received crushed Indocin ${ }^{\circledR}$ Cap (IND market product) $(25 \mathrm{mg} / \mathrm{kg})$ [43], and fourth group: Rats received selected IND-FDST, 04 ( $25 \mathrm{mg} / \mathrm{kg})$.

\section{Serum tumour necrosis factor-alpha (TNF- $\alpha$ ) and interleukin-6} (IL-6) determination

Serum levels of TNF- $\alpha$ and IL-6 were determined using EnzymeLinked Immunosorbent Assay (ELISA) kit. The manufacturer's instructions of the NOVA kit (Beijing, China) were followed, for calculating the results. Standards and samples were pipetted into wells with immobilized antibodies specific for rat TNF- $\alpha$ and IL-6, then were incubated for $30 \mathrm{~min}$ at $37^{\circ} \mathrm{C}$. After incubation and washing, horseradish peroxidase-conjugated streptavidin was pipetted into the wells and incubated for another $30 \mathrm{~min}$ at $37^{\circ} \mathrm{C}$, which were washed once again. Tetramethyl benzidine (TMB) substrate solution was added to the wells and incubated for $15 \mathrm{~min}$ at $37{ }^{\circ} \mathrm{C}$; colour developed proportionally to the amount of TNF- $\alpha$, and IL- 6 bound. Colour development was discontinued (using Stop Solution) and after 10 min colour intensity was measured at $450 \mathrm{~nm}$.

\section{Statistical analysis}

All the values are presented as means \pm SD of the means. Comparisons between different groups were carried out using ANOVA followed by the least significant difference (LSD) test for multiple comparisons using Minitab $17^{\circledR}$ software. The difference is considered significant when $\mathrm{p}<0.05$.

\section{RESULTS}

\section{QbD and screening study}

As shown in table 1, all tablets exhibited comparable thickness, diameter, and weight variation percentages with a smooth appearance. The tablets thickness and diameter ranged from $0.55 \pm 0.1 \mathrm{~cm}$ to $0.54 \pm 0.01 \mathrm{~cm}$ and $1.45 \pm 0.1 \mathrm{~cm}$ to $1.52 \pm 0.02 \mathrm{~cm}$, respectively. Weight variation ranged from $0.11 \pm 0.04$ to $0.95 \pm 0.12 \%$ (data not shown). The drug content of all the prepared tablets was adequate ranging from $97.31 \%$ to $99.14 \%$ thereby conforming to USP limits between 90 and $110 \%$.

Table 1: Composition of IND-FDSTs during QbD screening study and the respective results of $\%$ friability ( $n=10)$, drug content ( $n=5)$, and disintegration time $(n=6)^{*}$

\begin{tabular}{llllllll}
\hline Formula** $^{* *}$ & $\begin{array}{l}\text { Matrix } \\
\text { former }\end{array}$ & $\begin{array}{l}\text { Super } \\
\text { disintegrant }\end{array}$ & $\begin{array}{l}\text { Matrix former } \\
\text { (mg) }\end{array}$ & $\begin{array}{l}\text { Super disintegrant } \\
\text { (mg) }\end{array}$ & $\begin{array}{l}\text { Drug } \\
\text { content (\%) }\end{array}$ & $\begin{array}{l}\text { \% } \\
\text { Friability }\end{array}$ & $\begin{array}{l}\text { Disintegration time } \\
\text { (sec) }\end{array}$ \\
\hline S1 & Na alginate & CCS & 4 & 4 & $99.14 \pm 4.87$ & $0.13 \pm 0.01$ & $101.23 \pm 2.21$ \\
S2 & Na alginate & SSG & 4 & 4 & $98.11 \pm 2.61$ & $0.12 \pm 0.02$ & $115.13 \pm 1.23$ \\
S3 & Gelatin & CCS & 4 & 4 & $99.23 \pm 2.01$ & $0.73 \pm 0.03$ & $25.40 \pm 1.21$ \\
S4 & Gelatin & SSG & 4 & 4 & $98.23 \pm 1.53$ & $0.32 \pm 0.02$ & $119.00 \pm 3.21$ \\
S5 & Pectin & - & 0 & 4 & $99.21 \pm 1.32$ & $1.50 \pm 0.01$ & $62.34 \pm 4.51$ \\
S6 & - & - & 0 & 0 & $99.65 \pm 2.33$ & $1.75 \pm 0.23$ & $75.32 \pm 9.28$ \\
S7 & Gelatin & - & 4 & 0 & $99.65 \pm 0.33$ & $0.75 \pm 0.01$ & $125.22 \pm 12.63$ \\
S8 & Na alginate & CP & 4 & 4 & $97.23 \pm 0.57$ & $0.44 \pm 0.1$ & $129.79 \pm 15.31$ \\
S9 & Gelatin & CP & 4 & 4 & $99.00 \pm 1.31$ & $0.37 \pm 0.03$ & $118.00 \pm 22.86$ \\
S10 & Pectin & CCS & 4 & 4 & $99.14 \pm 2.68$ & $0.46 \pm 0.06$ & $137.26 \pm 23.21$ \\
S11 & Pectin & CP & 4 & 4 & $99.25 \pm 3.25$ & $0.25 \pm 0.02$ & $171.21 \pm 27.53$ \\
S12 & Pectin & SSG & 4 & 4 & $98.72 \pm 1.72$ & $0.16 \pm 0.05$ & $150.11 \pm 33.21$ \\
\hline
\end{tabular}

*Results are represented as mean $\pm \mathrm{SD}$, ${ }^{*}$ Each formula contained $25 \mathrm{mg}$ IND, $4 \mathrm{mg}$ glycine, $5 \mathrm{mg}$ sucralose, and mannitol was added so that the theoretical tablet weight is $200 \mathrm{mg}$.

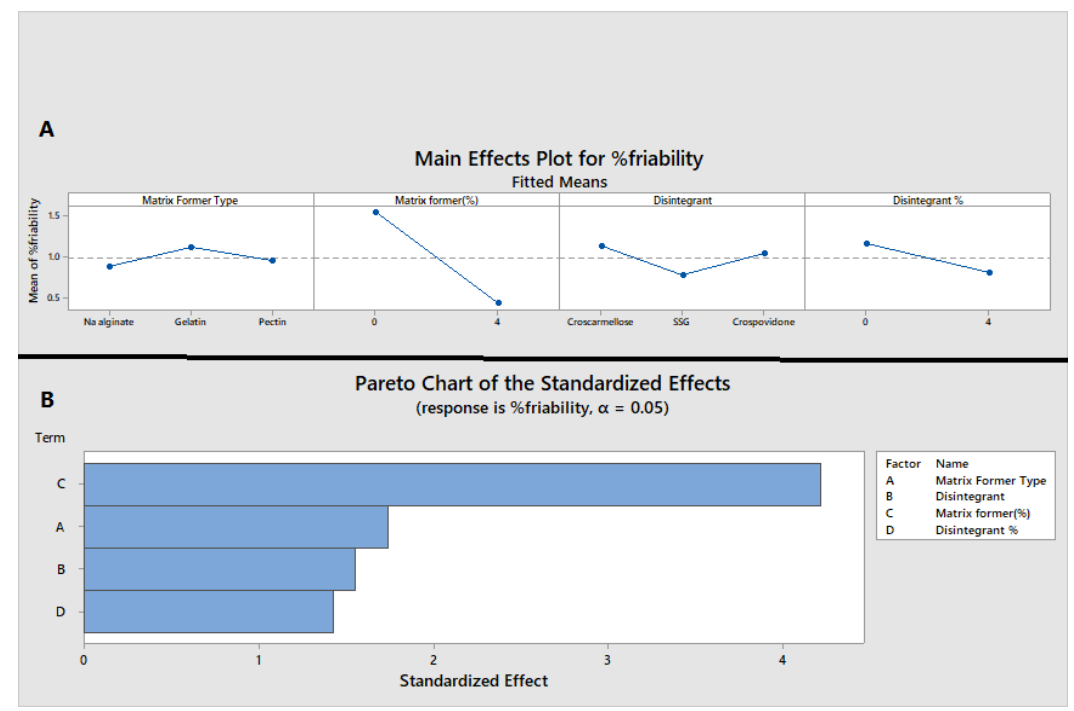

Fig. 2: Main effects plot (A) and Pareto Plot for (B) for \% friability during the screening study for preparing IND-FDST 
However, tablets prepared without matrix former were dusty and friable and showed pores on their surface indicative of the importance of the presence of a matrix former as a binder and to preserve tablet integrity. This result is also indicated in the Pareto plot (fig. 2B) which shows that the matrix former amount was the most significant factor affecting the \% friability compared to the other factors in this study. This fact is also reflected in friability results as tablets prepared without matrix former displayed a high friability percentage which does not conform to USP limits that should be less than $1 \%$ [29]. In addition, the main effects plot in (fig. $2 \mathrm{~A}$ ), which displays the effects of matrix former amount on friability, showed a significant friability decrease $(\mathrm{p}<0.05)$ upon the increasing amount of matrix former from 0 to $4 \mathrm{mg}$ indicative of the binding effect of the matrix former on the FDST which in turn preserve the tablet integrity. However, the type of matrix formers present in this study did not have a significant effect on the \% friability $(p>0.05)$. Nevertheless, sodium alginate showed the least \% friability followed by pectin, and the highest $\%$ friability was shown by the gelatin. The super disintegrant type and disintegrant amount had an insignificant effect on the $\%$ friability $(\mathrm{p}>0.05)$.

The importance of matrix former amount is also signified in disintegration time, which was also one of the most contributing factors as shown in Pareto Plot (fig. 3B) and main effects plot (fig. $3 \mathrm{~A}$ ). The plots showed a significant decrease in the disintegration time upon the addition of a matrix former $(\mathrm{p}<0.05)$ regardless of its type. The type of the matrix former showed an overall insignificant effect $(p>0.05)$ on the disintegration time. The addition of a super disintegrant significantly decreased the disintegration time $(\mathrm{p}<0.05)$ due to the increased wicking and subsequent decrease in breakage of the tablets. However, the types of the disintegrant had no significant effect on the disintegration time $(\mathrm{p}>0.05)$.

Based on the above results of the statistical design, the matrix former amount and super disintegrant amount are the most significant factors and thus will be included in the optimization study in the QbD process. To determine the most suitable matrix former and super disintegrant to be included in the optimization study. The desirability index (D) value of the prepared formulas was calculated to determine the most desirable combination of matrix former and super disintegrant for the optimization study. The results revealed that the gelatin/CCS combination showed the most desirable attributes (low \% friability and low disintegration time) and thus was included in the optimization study. As shown in fig. 4 , gelatin-based FDSTs showed the highest in vitro dissolution profile, followed closely by Na alginate, and least was pectin-based FDSTs.

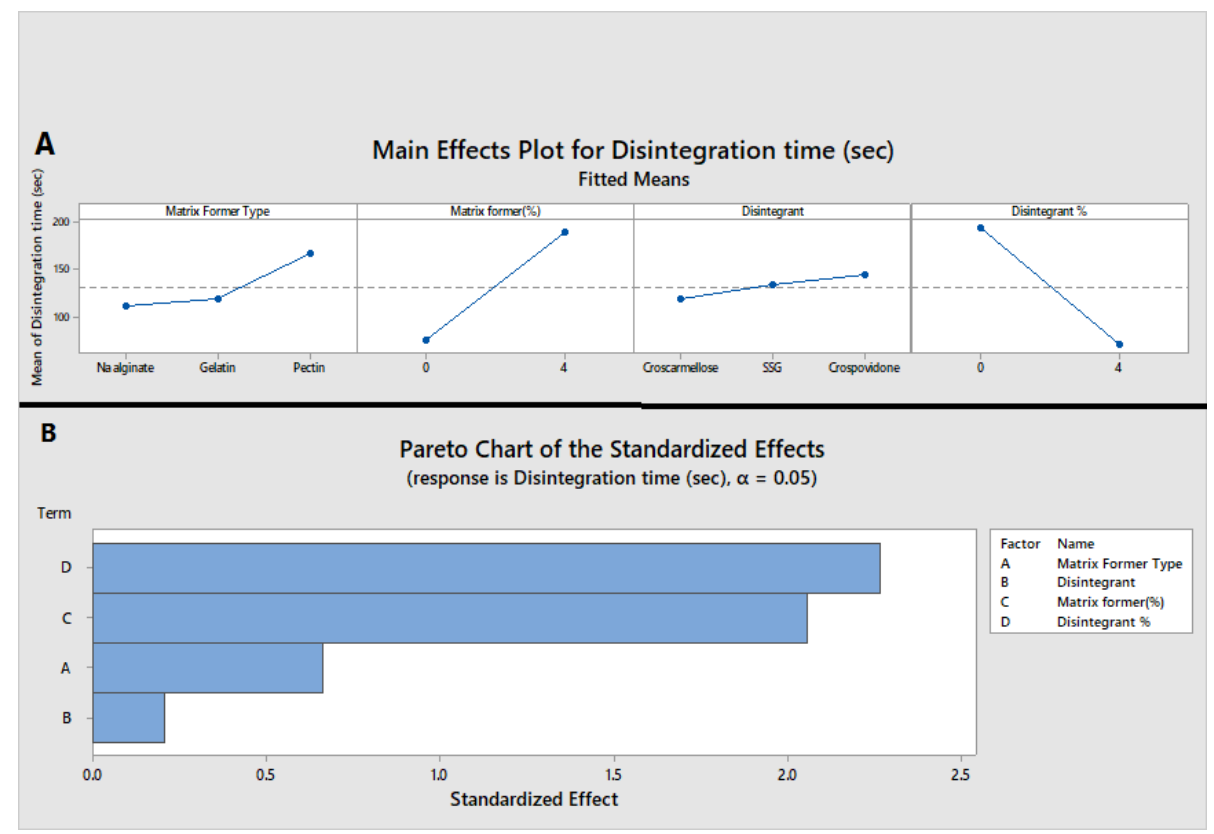

Fig. 3: Main effects plot (A) and Pareto Plot (B) for disintegration time during the screening study for preparing IND-FDST

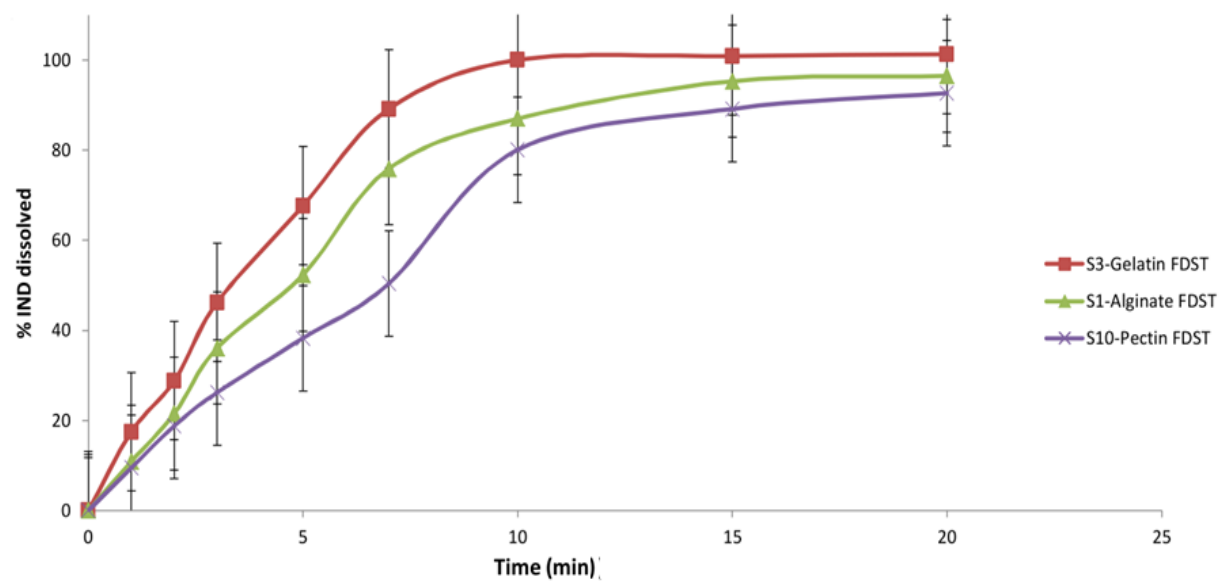

Fig. 4: Dissolution profiles of IND in USP media at $37 \pm 2^{\circ} \mathrm{C}$ for formulas $S 3$, S1, and S10 IND-FDST prepared during screening study (n=6) 


\section{Optimization study of IND-FDST}

Table (2) summarizes the results for IND-FDST formulas 01-09. As shown in the 3D plot for $\%$ friability (fig. $5 \mathrm{~A}$ ), friability was primarily affected by gelatin amount $(\mathrm{p}<0.05)$ contrary to the CCS amount $(p>0.05)$ which did not significantly affect the friability. In addition, an indirect relationship was observed between the gelatin amount and friability which decreases as gelatin amount increases in FDST from 0 to $8 \mathrm{mg}$. It is also worth noting that tablets with a gelatin amount lower than $4 \mathrm{mg}(01$ to 04$)$ exhibited friability \% higher than $1 \%$ which is non-conforming and out of specifications of the USP 39/NF 34 [29]. These results come in line with the screening study results and confirm the importance of matrix formers in FDST formulation.

Table 2: Composition of IND-FDSTs/tablet during response surface study and the results of \%Friability ( $n=10)$, Drug content ( $n=5)$, Disintegration time $(n=6)$, wetting time $(n=3)$ and $\% Q 10(n=6)^{*}$

\begin{tabular}{|c|c|c|c|c|c|c|}
\hline Formula* & Matrix former (mg) & $\begin{array}{l}\text { Super disintegrant } \\
\text { (mg) }\end{array}$ & Friability (\%) & $\begin{array}{l}\text { Disintegration } \\
\text { time (sec) }\end{array}$ & $\begin{array}{l}\text { Wetting time } \\
\text { (sec) }\end{array}$ & $\%$ Q10 \\
\hline 01 & 0.00 & 2.00 & $2.35 \pm 0.76$ & $62.34 \pm 5.31$ & $5.31 \pm 0.04$ & $83.12 \pm 1.21$ \\
\hline 02 & 2.00 & 0.00 & $1.68 \pm 0.54$ & $75.32 \pm 8.64$ & $6.31 \pm 0.12$ & $79.00 \pm 3.91$ \\
\hline 03 & 2.00 & 4.00 & $1.42 \pm 0.61$ & $20.32 \pm 1.91$ & $3.21 \pm 0.26$ & $72.00 \pm 1.09$ \\
\hline 04 & 4.00 & 4.00 & $0.73 \pm 0.03$ & $25.40 \pm 1.21$ & $3.49 \pm 0.68$ & $100.99 \pm 5.29$ \\
\hline 05 & 4.00 & 0.00 & $0.75 \pm 0.12$ & $123.45 \pm 22.76$ & $4.21 \pm 0.09$ & $65.21 \pm 2.01$ \\
\hline 06 & 4.00 & 8.00 & $0.56 \pm 0.04$ & $69.22 \pm 11,51$ & $4.48 \pm 0.53$ & $63.21 \pm 5.94$ \\
\hline 07 & 8.00 & 0.00 & $0.30 \pm 0.03$ & $251.12 \pm 32.98$ & $10.01 \pm 0.29$ & $55.61 \pm 1.26$ \\
\hline 08 & 8.00 & 4.00 & $0.26 \pm 0.04$ & $193.59 \pm 21.87$ & $3.17 \pm 0.41$ & $61.24 \pm 6.81$ \\
\hline 09 & 8.00 & 8.00 & $0.34 \pm 0.02$ & $332.12 \pm 52.75$ & $12.02 \pm 0.15$ & $57.22 \pm 2.73$ \\
\hline
\end{tabular}

${ }^{*}$ Results are represented as mean \pm SD.

Wetting time and disintegration time are predictably two closely related parameters that depend on the wetting properties of the polymers used in the formulation of FDSTs. This relationship is reflected in the main effects and contour plots of \% gelatin and CCS and their effect on the wetting and disintegration times (fig. 5B, 5C). The same pattern of change in disintegration and wetting times upon changing gelatin and CCS amounts is noticed. Gelatin amount significantly $(\mathrm{p}<0.05)$ affected both disintegration and wetting times. As the gelatin amount increased from 0 to $2 \mathrm{mg}$, the wetting time decreased. However, as the gelatin amount increased from 4 to $8 \mathrm{mg}$ an increase in the wetting and disintegration times of the tablets is noted.

Increasing the CCS amount has significantly decreased the disintegration and wetting time $(\mathrm{p}<0.05)$. Generally, disintegration time usually depends on the wetting properties of the super disintegrant causing its swelling and subsequent tablet disintegration [30]. However, the addition of $8 \mathrm{mg}$ CCS resulted in a significant increase in disintegration time $(\mathrm{p}>0.05)$.

Dissolution profile represented by \%Q10 also confirmed the significant effect of matrix former and super disintegrant amounts and ratios to each other on the dissolution of IND in FDSTs $(\mathrm{p}<0.05)$. As shown in the 3D plot (fig. 5D), the \% Q10 significantly increased by decreasing the amount of gelatin. The same holds for the super disintegrant amount with the \% Q10. These results come in agreement with the disintegration time curves that indicate that the optimum gelatin and CCS amounts are $4 \mathrm{mg}$ with a ratio of 1:1, which is required to achieve the fastest disintegration time and highest \% Q10.

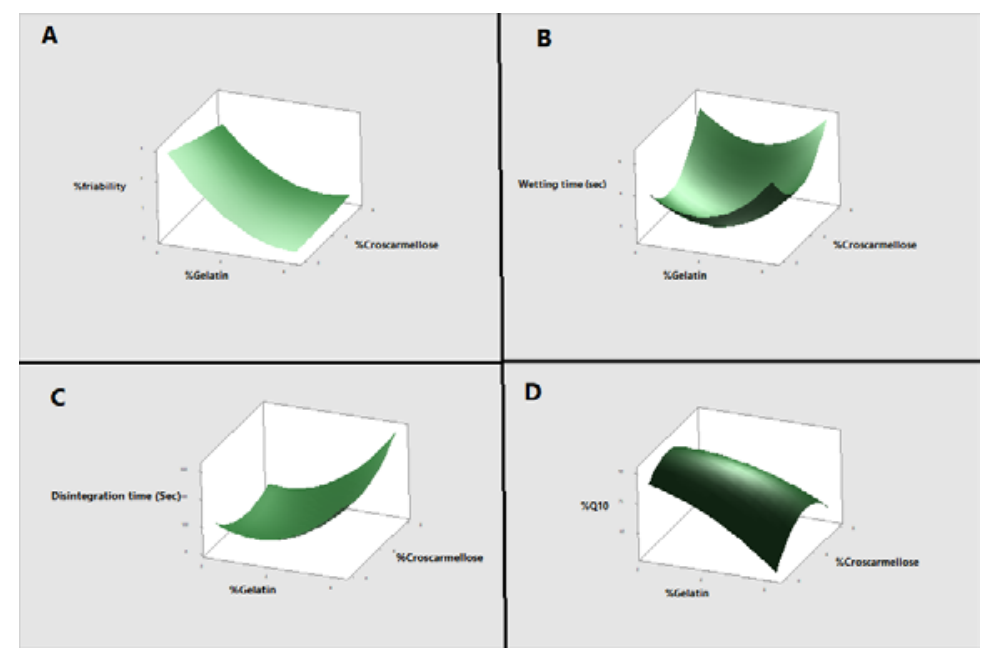

Fig. 5: 3D plots for the effect of Matrix former type and $\%$ as well as super disintegrant type and $\%$ on the (A) \%friability ( $n=3$ ) (B) wetting time (n=3), (C) disintegration time $(n=6)$, and (D) \%Q10 (n=10) of the predicted IND-FDST during optimization study

Upon optimization of the response surface design, Formula 04 which contained $4 \mathrm{mg}$ of gelatin and CCS was shown to be the most desirable formula with a D value of 0.718 . Thus, it will be progressed to the accelerated and in vivo studies.

Worthy of note, formula 04 complies with USP [29] specifications for official sublingual tablets formulations with disintegration time less than 2 min (25.42 seconds) and \% of drug released higher than
$80 \%$ in $20 \min (\%$ Q10 =100.99 \%), \% friability less than 1\% $(0.7$ $3 \pm 0.03 \%$ ). IND-FDST optimized formula 04 showed also comparable dimensions to those prepared during the screening study $(0.55 \pm 0.05 \mathrm{~cm}$ thickness and $1.35 \pm 0.05$ diameter $)$. As well as a drug content of $(99.23 \pm 2.01 \%)$ which falls within the USP [29] limits for acceptable drug content (90-110\%) and acceptable weight variation limit less than $5 \%(0.95 \pm 0.12 \%)$ is also shown for formula 04. 
Upon comparison of the dissolution profiles of 04 FDST and market product Indocin ${ }^{\circledR}$ capsules (fig. 6), it is evident that the FDST formula exhibited a faster dissolution profile than the market product confirmed by a similarity factor $<50 \quad(\mathrm{f} 2=33)$ indicating dissimilar dissolution profiles. This result can be explained by its faster disintegration which leads ultimately to faster dissolution.

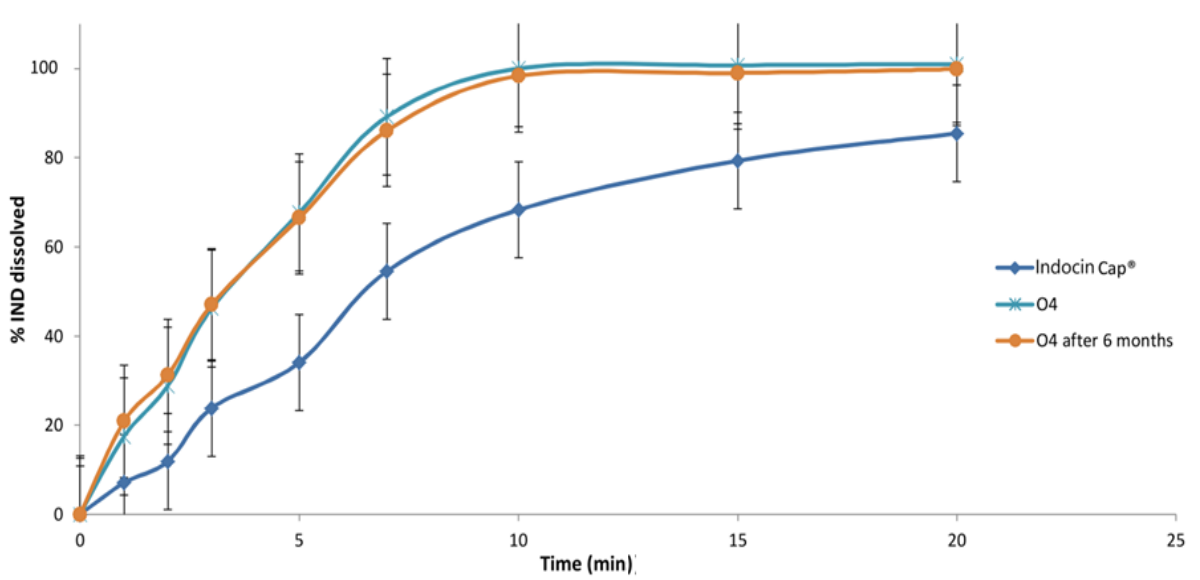

Fig. 6: Dissolution profiles of IND in USP media at $37 \pm 2^{\circ} \mathrm{C}$ for Indocin Cap ${ }^{\circledR}$ market product, optimized IND-FDST formula 04 freshly prepared and after 6 mo $(n=6)$

\section{Evaluation of optimized IND-FDST}

\section{Differential scanning calorimetry (DSC)}

As shown in DSC thermograms, fig. 7, pure IND shows one sharp prominent endothermic peak observed at $159.99^{\circ} \mathrm{C}$ indicating the melting transition point of the $\gamma$ crystalline form of the drug [44]. The physical mixture shows a peak with low intensity at $159.5^{\circ} \mathrm{C}$ for the drug and another peak at $166.5^{\circ} \mathrm{C}$ which corresponds to the mannitol. 04 FDST showed no peaks at the drug melting transition temperature $\left(159.5^{\circ} \mathrm{C}\right)$, and another broader endothermic peak was observed at $163.5^{\circ} \mathrm{C}$.

\section{Powder X-ray diffraction (XRD)}

Fig. 8 shows the X-ray diffraction peaks for pure IND, FDST 04, and its corresponding physical mixture. XRD checks the crystallinity of the substance. IND is a crystalline drug where, the $\gamma$-crystalline form (most stable) diffraction pattern shows sharp peaks at $2 \theta 11.6^{\circ}$, $16.4^{\circ}, 19.6^{\circ}, 21.7^{\circ}, 26.89^{\circ}$, and $29.3^{\circ}$. The diffraction pattern of the FDST (04), shows a decrease in the intensity of the drug peaks at $2 \theta$ $21.7^{\circ}, 26.89^{\circ}$ as well as some changes in the position of the peaks are observed.

\section{Fourier-transform infrared spectroscopy (FT-IR)}

Fig. 9 shows the infrared spectroscopy of indomethacin, FDST 04 and its corresponding physical mixture, and all the components of the tablet. Generally, the FT-IR is used to determine the presence of any interaction between the drug and the tablet components at room temperature. The IR spectrum of indomethacin shows characteristic bands in the following wavenumbers: $1716 \mathrm{~cm}^{-1}$ for $(\mathrm{C}=0)$ in the $\mathrm{COO}$ group, 1625-1575 and $1479 \mathrm{~cm}^{-1}$ for (C-C) stretching of the aromatic rings, $1692 \mathrm{~cm}^{-1}$ for amide group, 1261-1223 cm-1, below 1012 and $737 \mathrm{~cm}^{-1}$ for $(1 / 4 \mathrm{C}-\mathrm{O})$ of the ether group, (C-H) deformation, and (C-C) stretching modes, and 2927 and $2966 \mathrm{~cm}^{-1}$ for $\left(\mathrm{CH}_{2}\right)$ [36, 45, 46]. The bands present in the FTIR of the individual components superposed in the IND-FDST FTIR chart without the appearance of new peaks or disappearance of an existing peak of the drug significant peaks in FDST 04 and its corresponding physical mixture.

\section{Scanning electron microscopy (SEM)}

The SEM micrographs (fig. 10) illustrate the highly porous structure of FDST 04 which provides an excellent path for the water. In turn, this allows fast hydration of the formula to show rapid disintegration, enhanced IND released percentage, and dissolution rate.

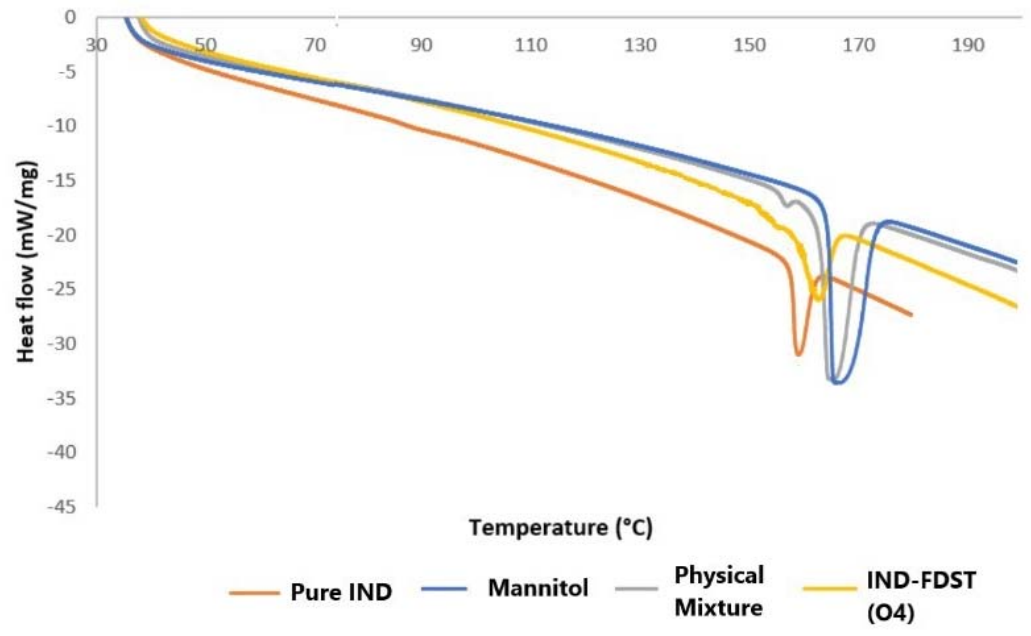

Fig. 7: DSC thermogram of Pure IND, IND-FDST optimized formula (04), and physical mixture 


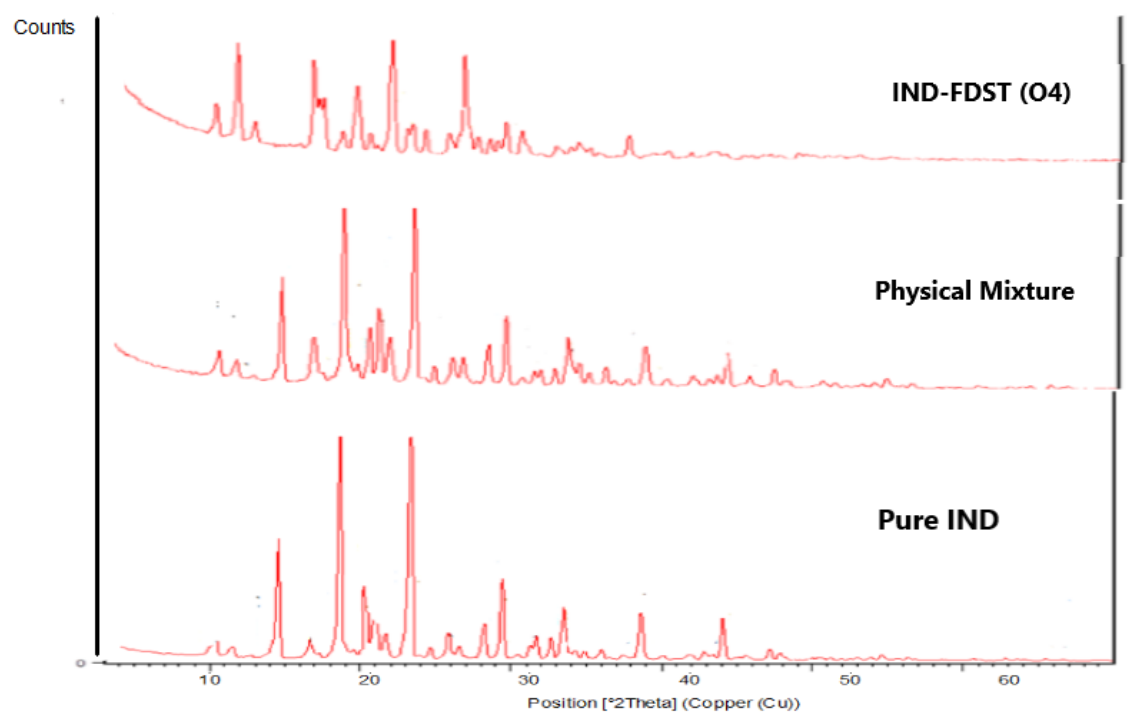

Fig. 8: XRD diffractogram of pure IND, IND-FDST optimized formula (04), and physical mixture

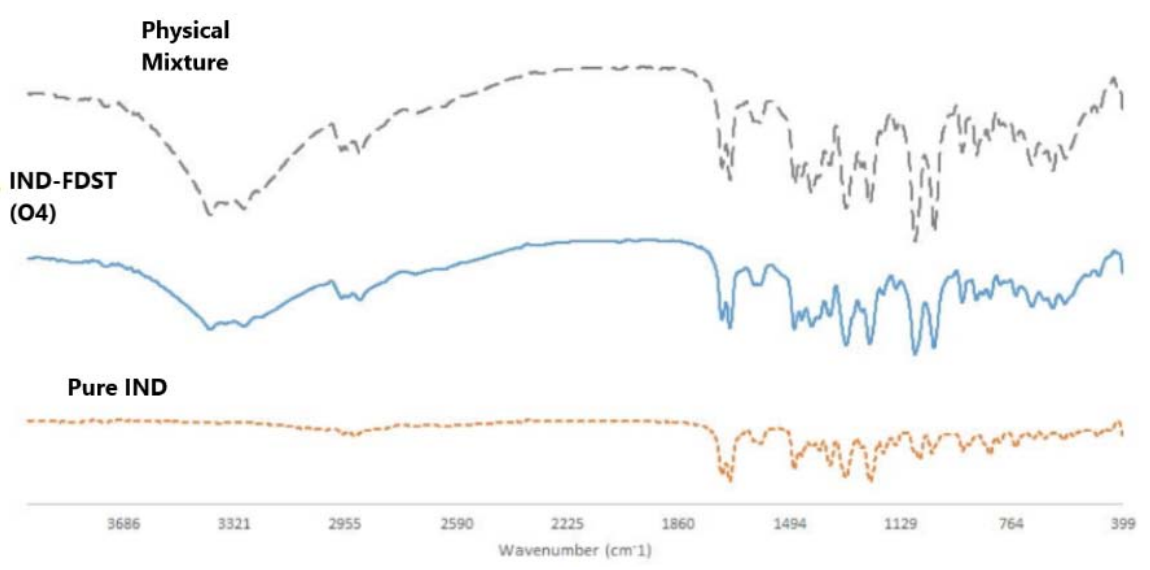

Fig. 9: FTIR diffractogram (C) of Pure IND, IND-FDST optimized formula (04), and physical mixture
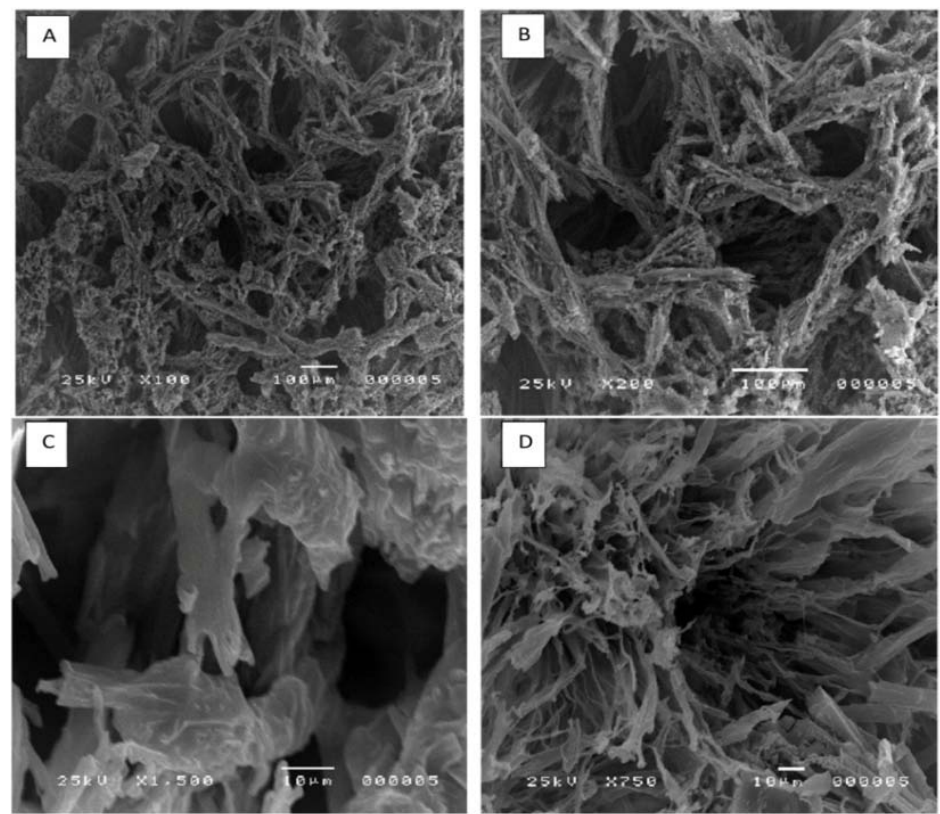

Fig. 10: SEM micrographs of IND-FDST optimized formula (04) 


\section{Accelerated stability study}

Stability of FDST tablets 04 was done to assess the effect of storage on the stability of FDST tablets under accelerated stability conditions $\left(40 \pm 2^{\circ} \mathrm{C} / 75 \pm 5 \% \mathrm{RH}\right)$ according to ICH guidelines [38]. IND-FDST (04) has shown adequate stability and insignificant changes to the tested attributes and retained residual drug content of $97.21 \pm 3.15 \%$ from the fresh FDST. The change was within the $5 \%$ limit specified by the ICH. Moreover, the tablet disintegration time and $\%$ friability insignificantly ( $\mathrm{p}>0.05$ ) changed from $25.40 \pm 1.21$ seconds to $26.21 \pm 0.91$ seconds and from $0.73 \pm 0.03 \%$ to $0.77 \pm 0.1 \%$, respectively. These results confirm the ability of the freeze-dried dosage forms to preserve IND stability.

The dissolution profile (fig. 3) represented by \% Q10 changed from $100.99 \pm 5.29 \%$, for the fresh FDST to $99.83 \pm 3.17 \%$ for stored tablets with similarity factor $\mathrm{f} 2>50(\mathrm{f} 2=83)$. Thereby, the dissolution profile of the stored tablets comes to confirm the stability of the tablet quality attributes and properties throughout the storage period.

\section{In vivo anti-inflammatory effects \\ Carrageenan induced paw edema}

The sub-planter injection of $100 \mu \mathrm{l}$ of $1 \%$ sterile carrageenan into the rat hind paw elicited an inflammation (swelling and erythema). A time-dependent increase in paw edema by $40 \%, 52 \%, 97 \%$, and $94 \%$ in the $1^{\text {st }}, 2^{\text {nd }}, 3^{\text {rd }}$, and $4^{\text {th }}$ hours, respectively, was observed as compared with pre-carrageenan control values. The application of IND oral suspension and FDST 04 showed significant inhibition of the edema formation at the $4^{\text {th }}$ hour by $36 \%$ and $70 \%$, respectively, as compared with the carrageenan control group at the same time. In addition, the application of FDST 04 showed significant inhibition of edema formation in the $4^{\text {th }}$ hour by $54 \%$ compared with the free drug.

Table 3: Effects of IND-FDST optimized formula (04) compared to Indocin ${ }^{\circledR}$ Cap market product, negative and positive control on TNF- $\alpha$ and IL- 6 in rats $(n=10)^{*}$

\begin{tabular}{lllc}
\hline & Negative control & Positive control & Indocin $^{\circledR}$ Cap \\
\hline TNF- $\alpha(\mathrm{pg} / \mathrm{ml})$ & $525.00 \pm 7.50$ & $978.75 \pm 11.25$ & $816.25 \pm 1.25$ \\
IL-6 $(\mathrm{pg} / \mathrm{ml})$ & $83.00 \pm 16.84$ & $245.80 \pm 28.61$ & $135.60 \pm 3.13$ \\
\hline
\end{tabular}

${ }^{*}$ Results are represented as mean \pm SD.

\section{Effects of IND-FDST on tumour necrosis factor-alpha (TNF- $\alpha$ ) and interleukin-6 (IL-6)}

As shown in table 3, carrageenan-induced an increase in the inflammatory cytokine release (positive control) namely, TNF- $\alpha$ by $86 \%$ and IL- 6 by 2 -fold as compared with the normal control group. The application of pure IND and FDST 04 showed significant inhibition of TNF- $\alpha$ release by $17 \%$ and $42 \%$, and IL- 6 release by $45 \%$ and $65 \%$, respectively, as compared with the carrageenan control group, table 7. Therefore, the application of FDST 04 showed significant inhibition of TNF- $\alpha$ and IL- 6 release by $31 \%$ and $37 \%$, respectively, as compared with free drugs.

\section{DISCUSSION}

With the aim of preparing fast disintegrating sublingual tablets, Freeze-drying was chosen as a preparation technique. Tablets produced by freeze-drying are of high porosity which allows better exposure of the drug to the dissolution media (saliva in mouth). As a result, an immediate disintegration and dissolution of the tablet occur when placed under the tongue [11-16]. The tablet excipients were carefully selected to serve the aim of the research paper in providing a rapid and safe therapeutic action. The selected matrixforming polymers are from natural sources and have a considerably good water solubility to allow rapid tablet dissolution. The other components of the tablets are held very well within the matrix of the polymer, which in turn affects the tablet's physical strength (\% friability). The presence of a super disintegrant significantly decreased the disintegration time $(p<0.05)$ due to the increased wicking and subsequent breakage of the tablets. Other additives were used to enhance the appearance, physical strength, and taste of the tablet. Glycine was added as it acts as a cryoprotectant to prevent the shrinkage of the tablet after freeze-drying. Sucralose was used as a sweetener to enhance the taste of the formula. Finally, mannitol was employed as a filler. In addition, mannitol possesses a well-established cryoprotectant ability as it crystallizes during freezing thereby protecting the tablet components from degradation while simultaneously offering an elegant appearance [16]. Besides, the high water solubility of the selected filler also improves the mouthfeel, texture, and taste of the formula [11].

Based on the literature review and preliminary studies, the selection of a good matrix-forming polymer and a compatible super disintegrant is the key to a successful fast disintegrating sublingual tablet (IND-FDST) formulation. As such, A QbD design was employed to screen the most significant formulation attributes for an optimization study namely lower $\%$ friability and disintegration time. The screening study focused on studying different variables namely (matrix former type and amount, disintegrate type and amount) to determine the best matrix former/super disintegrant combination for the optimization study. Friability was chosen as a critical attribute to assess the success of tablet formulation in terms of its ability to withstand handling. In addition, disintegration time was chosen as a second critical attribute as rapid tablet disintegration ensures immediate dissolution and dispersibility in the oral cavity.

The gelatin and CCS were selected as the best matrix former and super disintegrant, respectively. The combination of the two polymers in the tablet provided a low \% friability and rapid disintegration time from the screening study. This can be explained by the ability of the matrix former to hold the tablet components together to give enough physical strength to the tablet. In addition, the hydrophilic nature of the binder and CCS allow fast wetting of the tablet, and hence rapid disintegration is observed. Based on the results of the screening design, the gelatin and CCS amount were noted as the most significant factors and thus were included in the optimization study in the QbD process.

During the optimization study, wetting time and disintegration time were predictably found to be two closely related parameters that depend on the wetting properties of the polymers used in the formulation of FDSTs. It has been observed that the disintegration time usually depends on the wetting properties of the super disintegrant causing its swelling and subsequent tablet disintegration [30]. This relationship has been highlighted during the optimization study. Gelatin amount significantly $(\mathrm{p}<0.05)$ affected both disintegration and wetting times.

In the absence of gelatin $(0 \mathrm{mg})$, the IND-FDST failed to properly bind and was very fragile, therefore it was rejected. At a low gelatin amount $(2 \mathrm{mg})$, the wetting time decreased probably due to the impaired binding effect of the polymer on the tablet components, being used in a small amount, causing them to disintegrate rapidly [30]. In addition, this amount showed a high \% friability above the acceptable values. The \% Q10 was relatively low this can be explained by the high friability of the tablets which leads to the loss of an amount of the drug during handling, therefore the inability to fully release the drug though it has a fast disintegration time may be logical.

However, as the gelatin amount increased to $4 \mathrm{mg}$, more tablet binding and proper holding of the tablet components within the polymer matrix were observed. This is reflected by the acceptable $\%$ friability percentages with a very subtle increase in the wetting and disintegration time of the tablets, and a higher \%Q10, which makes this amount of gelatin the optimum. 
Further increase in the gelatin amount ( $8 \mathrm{mg}$ ) significantly increased the tablet wetting and disintegration time to be above the accepted values for the sublingual tablets. In addition to the low percentage of drug release. This is expected due to gelatin crosslinking that causes the formation of a swollen, water-insoluble pellicle which acts as a barrier and restricts the release of the drug [47]. Generally, in FDSTs the fast disintegration and dissolution of the drug are prioritized to allow the latter rapid absorption through the oral mucosa $[6,48]$.

Increasing CCS amount has significantly decreased the disintegration and wetting time $(\mathrm{p}<0.05)$ due to the wicking and super disintegrant action of CCS which causes faster disintegration of tablets. Surprisingly, the addition of $8 \mathrm{mg}$ CCS resulted in a significant increase in disintegration time $(p>0.05)$. However, this effect was previously reported and can be explained by the partial gelling that potentially could form a viscous barrier and delay the entry of water into the tablet thereby increasing the disintegration time [49].

Therefore, based on the previously discussed factors, the optimum amount for the gelatin and CCS in IND-FDST is $4 \mathrm{mg}$ for each polymer present in formula 04 , where this amount provides a low $\%$ friability $(0.73 \pm 0.03 \%)$, adequate wetting time ( $3.49 \pm 0.68$ seconds), disintegration time $(25.40 \pm 1.21$ seconds $)$, and $\%$ Q10 $(100.99 \pm 5.29 \%)$. The optimized formula IND-FDST 04 exhibited faster dissolution profiles compared to market product Indocin ${ }^{\circledR}$ capsules which are explained by its faster disintegration, leading to the faster dissolution of the IND. The faster disintegration can be attributed to the choice of the optimized ratio of gelatin/CCS as well as the freeze-drying technique for the tablet preparation, which is known for its ability to form porous, fast-dissolving cakes, making it a method of choice for the preparation of fast dissolving sublingual tablets. The high porosity of the 04 formula was confirmed by SEM micrographs (fig. 4D) [30, 50].

The physical-pharmaceutical tests performed as supportive evidence for the enhanced performance of the optimized FDST 04. The enhanced dissolution profile may be attributed to the probability of the presence of IND in an amorphous form which is known to have a faster dissolution rate than crystalline forms [51]. This probability was confirmed by DSC which suggests the presence of IND in a solubilized or amorphous form probably as a result of the freeze-drying process indicated by the disappearance of the IND endothermic peak in the 04 formula [30]. XRD confirmed the change of the crystalline structure of IND to a molecularly dispersed form in the tablet matrix explained by the decrease in the peak intensity and the slight shifting of the peaks $[11,52]$. FTIR confirmed the absence of chemical interaction between the formula components at room temperature illustrated by the absence of any changes in IND characteristic peaks in the 04 IND-FDST FTIR diffractogram [28]. IND-FDST optimized formula (04) also exhibited stability under accelerated conditions thereby enforcing the successful preparation of the optimized IND-FDST formula with characteristics suitable to be industrialized and marketed to the patients.

Inflammatory response induced by carrageenan stimulates the secretion of inflammatory cytokine [53]. Therefore, blood samples were withdrawn from the rats for the assessment of the level of inflammatory cytokines (TNF- $\alpha$, and IL-6). The in vivo antiinflammatory effects in rats confirmed the increased efficacy of the IND-FDST tablets compared to IND suspension. The better control of the formula FDST 04 on the paw edema in comparison to the oral suspension of the drug may be correlated to the rapid release and absorption of the drug. The rapid absorption is explained by the improved solubility of IND in the formula as illustrated by the increased in vitro dissolution of the IND-FDST. In addition, the sublingual route exhibits high vascularity as the drug is absorbed from the mouth floor veins leading directly to the superior vena cava combined with the thin epithelial cell lining of the mucosa. All these factors contribute to the faster absorption of IND and distribution of the drug to various body tissues leading to a faster onset of drug action [54]. Moreover, the better inhibitory effect of the formula FDST 04 on the inflammatory markers relative to the oral suspension may be correlated to the enhanced drug solubility and faster onset of action. Therefore, it may take the oral route a longer duration to reach a similar inhibitory level of the markers. The results also suggest a higher bioavailability of IND when administered as FDST compared to the market product due to its superior pharmacodynamics implied by the increased antiinflammatory effects in rats.

\section{CONCLUSION}

Based on the presented results, it can be concluded the QbD is a successful approach in optimization of a stable IND-FDST formula that surpasses the commercial oral IND tablets both in vitro and in vivo with the added advantage of reducing the unpleasant GIT side effects present in the oral tablets. IND-FDST prepared using gelatin/CCS combination with ratio 1:1 showed adequate tablet properties with better dissolution profile as well as good stability under accelerated conditions. IND-FDST tablets displayed significantly higher anti-inflammatory effects in vivo compared to the market product confirming its successful formulation. The authors recommend a further in vivo pharmacokinetic evaluation to assess the absorption, and bioavailability of IND-FDST compared to market product.

\section{FUNDING}

Nil

\section{AUTHORS CONTRIBUTIONS}

All authors have contributed equally.

\section{CONFLICT OF INTERESTS}

\section{Declared none}

\section{REFERENCES}

1. Parhi R. Improvement of dissolution rate of indomethacin from fast dissolving tablets. Indones J Pharm 2014;25:198.

2. Krishnaiah YSR, Karthikeyan RS, Satyanarayana V. A three-layer guar gum matrix tablet for oral controlled delivery of highly soluble metoprolol tartrate. Int J Pharm 2002;241:353-66.

3. Prabhu P, Malli R, Koland M, Vijaynarayana'SKuza U, Harish $\mathrm{N}$, et al. Formulation and evaluation of fast dissolving films of levocitirizine di hydrochloride. Int J Pharm Investig 2011;1:99.

4. Habib KE, Weld KP, Rice KC, Pushkas J, Champoux M, Listwak S, et al. Oral administration of a corticotropin-releasing hormone receptor antagonist significantly attenuates behavioral, neuroendocrine, and autonomic responses to stress in primates. Proc Natl Acad Sci USA 2000;97:6079-84.

5. Hua S. Advances in nanoparticulate drug delivery approaches for sublingual and buccal administration. Front Pharmacol 2019;10:1-9.

6. Tayel SA, El Nabarawi MA, Amin MM, AbouGhaly MHH. Comparative study between different ready-made orally disintegrating platforms for the formulation of sumatriptan succinate sublingual tablets. AAPS PharmSciTech 2017;18:410-23.

7. Aboutaleb AE, Abdel Rahman SI, Ahmed MO, Younis MA. Design and evaluation of domperidone sublingual tablets. Int J Pharm Pharm Sci 2016;8:195-201.

8. Sahoo S, Malviya K, Makwana A, Mohapatra PK, Sahu AR. Formulation, optimizationand evaluation of sublingual film of enalapril maleate using 32 full factorial design. Int J Appl Pharm 2021;13:178-86.

9. Thayyilakandy S, Gayathri PS, Arjun KK, Krishnakumar G, Nair SC. Fast dissolving sublingual patch of phenobarbital sodium: Formulation and in vitro evaluation. Int J Appl Pharm 2020;12:158-65.

10. Swapna K, Aparna C, Srinivas P. Formulation and evaluation of montelukast sodium and levocetirizine dihydrochloride sublingual tablets. Asian J Pharm Clin Res 2015;8:171-5.

11. Abd Elbary A, Ali AA, Aboud HM. Enhanced dissolution of meloxicam from orodispersible tablets prepared by different methods. Bull Fac Pharm Cairo Univ 2012;50:89-97.

12. Shoukri RA, Ahmed IS, Shamma RN. In vitro and in vivo evaluation of nimesulide lyophilized orally disintegrating tablets. Eur J Pharm Biopharm 2009;73:162-71. 
13. Yir-Erong B, Bayor MT, Ayensu I, Gbedema SY, Boateng JS. Oral thin films as a remedy for noncompliance in pediatric and geriatric patients. Ther Delivery 2019;10:443-64.

14. Ali BE, Rabba AK, Fayed MH, El-Say KM, Anwer MK, Ansari MJ, et al. Development and optimization of fluoxetine orally disintegrating tablets using box-behnken design. Trop J Pharm Res 2016;15:667-77.

15. Mahmoud AA, Salah S. Fast relief from migraine attacks using fast-disintegrating sublingual zolmitriptan tablets. Drug Dev Ind Pharm 2012;38:762-9.

16. Kassem AA, Labib GS. Flash dissolving sublingual almotriptan malate lyotabs for management of migraine. Int J Pharm Pharm Sci 2016;9:125.

17. Fokunang C. Overview of non-steroidal anti-inflammatory drugs (nsaids) in resource limited countries. MOJ Toxicol 2018;4:5-13.

18. Patel KM, Biswajit B, Karna N, Patel J. Preparation and evaluation of sustain release indomethacin tablets using skimmed milk and povidone. Int J Curr Pharm Res 2011;3:7-9.

19. Baber N, Halliday LDC, Van Den Heuvel WJA, Walker RW, Sibeon R, Keenan JP, et al. Indomethacin in rheumatoid arthritis: clinical effects, pharmacokinetics, and platelet studies in responders and nonresponders. Ann Rheum Dis 1979;38:128-36.

20. Bruckner FE, Randle APH. The use of indomethacin in rheumatoid arthritis. Rheumatology 1965;8:100-2.

21. Calabro JJ, Londino AVJ, Eyvazzadeh C. Sustained-release indomethacin in the management of the acute painful shoulder from bursitis and/or tendinitis. Am J Med 1985;79:32-8.

22. Gliszczyńska A, Nowaczyk M. Lipid formulations and bioconjugation strategies for indomethacin therapeutic advances. Molecules 2021;26:1576.

23. Lichtenberger LM, Romero JJ, Dial EJ. Gastrointestinal safety and therapeutic efficacy of parenterally administered phosphatidylcholine-associated indomethacin in rodent model systems. Br J Pharmacol 2009;157:252-7.

24. Bjarnason I, Scarpignato C, Holmgren E, Olszewski M, Rainsford $\mathrm{KD}$, Lanas A. Mechanisms of damage to the gastrointestinal tract from nonsteroidal anti-inflammatory drugs. Gastroenterology 2018;154:500-14.

25. Elkady OA, Tadros MI, El-laithy HM. QbD approach for novel crosslinker-free ionotropic gelation of risedronate sodiumchitosan nebulizable microspheres: Optimization and Characterization; 2020.

26. ICH Q8. EMEA/CHMP, 2009, ICH Topic Q 8 (R2) Pharmaceutical development, Step 5: Note for guidance on pharmaceutical development; 2009. p. 8. Available from: http://www.ema.europa.eu/docs/en_GB/document_library/Sc ientific_guideline/2010/01/W C500059258.pdf, http://www.ema.europa.eu/docs/en_GB/document_library/Sc ientific_guideline/2009/09/WC500002872.pdf. [Last accessed on 24 Jul 2017]

27. Mandlik SK, Agarwal PP, Dandgavhal HP. Implementation of quality by design (Qbd) approach in formulation and development of ritonavir pellets using extrusion spheronization method. Int J Appl Pharm 2020;12:139-46.

28. Malik R, Kumar S, Choudhary N, Choudhary M, Budhwar V. Formulation and evaluation of fast disintegrating tablet of telmisartan. J Chem Pharm Res 2016;8:61-7.

29. The United States pharmacopeia 39/National Formulary 34, The United States pharmacopeial convention Inc. Rockville, MD; 2016.

30. El-Laithy HM, Badawi A, Abdelmalak NS, Elsayyad NME. Stabilizing excipients for engineered clopidogrel bisulfate procubosome derived in situ cubosomes for enhanced intestinal dissolution: stability and bioavailability considerations. Eur J Pharm Sci 2019;136:104954.

31. Singh J, Garg R, Gupta G Das. Enhancement of solubility of lamotrigine by solid dispersion and development of orally disintegrating tablets using 32 full factorial design. J Pharm $2015 ; 2: 1-8$

32. Talluri M, Saha S, Adahalli SB. Development and evaluation of sublingual tablet of zolpidem tartrate an antipsychotic drug. Int J Pharm Pharm Sci 2016;8:179-87.
33. Javadzadeh Y, Shariati H, Movahhed Danesh E, Nokhodchi A. Effect of some commercial grades of microcrystalline cellulose on flowability, compressibility, and dissolution profile of piroxicam liquisolid compacts. Drug Dev Ind Pharm 2009;35:243-51.

34. Moore JW, Flanner HH. Mathematical comparison of curves with an emphasis on in vitro dissolution profiles. Pharm Technol 1996;20:64-74.

35. Venkateswarlu K, Thirumalesh Naik SB, Chandrasekhar KB. Formulation and in vitro evaluation of orlistat orodispersible tablets for enhancement of dissolution rate. Int J Pharm Pharm Sci 2016;8:236-41.

36. Abdel Halim S. Formulation of new sildenafil citrate-caffeine orally disintegrating tablets: in vitro and in vivo evaluation. J Pharm Res Opin 2013;3:46-63.

37. El-Setouhy DA, Basalious EB, Abdelmalak NS. Bioenhanced sublingual tablet of drug with limited permeability using novel surfactant binder and microencapsulated polysorbate: in vitro/in vivo evaluation. Eur J Pharm Biopharm 2015; 94:386-92.

38. International Conference on Harmonization, (2003) Q1A(R2): Stability testing of new drug substances and products (second revision), EU: adopted by CPMP; 2003. p. 65717-18.

39. Elsayyad NME, Salama A, Noshi SH. Concurrent tissue engineering and infection prophylaxis utilising stable dual action amoxicillin loaded scaffolds. J Drug Delivery Sci Technol 2020;58:101788.

40. Winter CA, Risley EA, Nuss GW. Carrageenin-induced edema in hind paw. Exp Biol Med 1962;3:544-7.

41. Abd El-Alim SH, Kassem AA, Basha M, Salama A. Comparative study of liposomes, ethosomes and transfersomes as carriers for enhancing the transdermal delivery of diflunisal: in vitro and in vivo evaluation. Int J Pharm 2019;563:293-303.

42. El Kady WM, Salama AAA, Desoukey SY, Hagag EG, El-Shenawy SM, El-Shanawany MA. Comparative DNA profiling, botanical identification and biological evaluation of gazania longiscapa DC and gazania rigens L. Bull Fac Pharm Cairo Univ 2015;53:129-45.

43. Kunes M, Kvetina J, Bures J. Type and distribution of indomethacin-induced lesions in the gastrointestinal tract of rat. Neuro Endocrinol Lett 2009;30:96-100.

44. Lin HL, Zhang GC, Huang YT, Lin SY. An investigation of indomethacin-nicotinamide cocrystal formation induced by thermal stress in the solid or liquid state. J Pharm Sci 2014;103:2386-95.

45. Soltani B, Nabipour H, Ahmadi Nasab N. Fabrication, controlled release, and kinetic studies of indomethacin-layered zinc hydroxide nanohybrid and its effect on the viability of HFFF2. J Dispers Sci Technol 2018;39:1200-7.

46. Stukelj J, Svanback S, Kristl J, Strachan CJ, Yliruusi J. Imagebased investigation: biorelevant solubility of $\alpha$ and $\gamma$ indomethacin. Anal Chem 2019;9:3997-4003.

47. Singh S, Rao KVR, Venugopal K, Manikandan R. Alteration in dissolution characteristics of gelatin-containing formulations: a review of the problem, test methods, and solutions. Pharm Technol North Am 2002;26:36-58.

48. Borges AF, Silva C, Coelho JFJ, Simoes S. Oral films: status and future perspectives: I-galenical development and quality attributes. J Controlled Release 2015;206:1-19.

49. Desai PM, Er PXH, Liew CV, Heng PWS. Functionality of disintegrants and their mixtures in enabling fast disintegration of tablets by a quality by design approach. AAPS PharmSciTech 2014;15:1093-104.

50. Gugulothu D, Desai P, Pandharipande P, Patravale V. Freeze drying: exploring potential in development of orodispersible tablets of sumatriptan succinate. Drug Dev Ind Pharm 2015;41:398-405.

51. Hiroyuki I, Nambu N, Tsuneji N. Stability and several physical properties of amorphous and crystalline forms of indomethacin. Chem Pharm Bull 1977; 57:364-70.

52. Pan X, Julian T, Augsburger L. Quantitative measurement of indomethacin crystallinity in indomethacin-silica gel binary system using differential scanning calorimetry and X-ray 
powder diffractometry. AAPS PharmSciTech 2006;7:E72E78.

53. Amdekar S, Roy P, Singh V, Kumar A, Singh R, Sharma P. Antiinflammatory activity of lactobacillus on carrageenan-induced paw edema in male wistar rats. Int J Inflam 2012;2012:752015.
54. Trindade PAK, Giglio FPM, Colombini Ishikiriama BL, Calvo AM, Modena KCS, Ribeiro DA, et al. Comparison of oral versus sublingual piroxicam during postoperative pain management after lower third molar extraction. Int J Oral Maxillofac Surg 2011;40:292-7. 